\title{
The Association between Polymorphism of CARD8 rs2043211 and Susceptibility to Arteriosclerosis Obliterans in Chinese Han Male Population
}

\author{
Kun Zhanga,b Wei Song ${ }^{c}$ Dalin Lib Jingqiang Yan ${ }^{b}$ Yunhui Chen ${ }^{b}$ Haoshan Qi ${ }^{b}$ \\ Juncheng Zhao ${ }^{b}$ Xing Jin ${ }^{a}$ \\ aDepartment of Vascular Surgery, Shandong Provincial Hospital affiliated to Shandong University, \\ Jinan, Shandong, 'Department of Vascular Surgery, Qingdao Municipal Hospital, Qingdao, Shandong, \\ 'Department of Endocrinology, Qingdao Municipal Hospital, Qingdao, Shandong, P.R. China
}

\section{Key Words}

Arteriosclerosis obliterans $\bullet$ Card8 $\bullet$ Polymorphism $\bullet$ IL-1及

\begin{abstract}
Background and aims: Cholesterol crystals have been shown to cause inflammation. As a response to cholesterol crystal accumulation, the NLRP3 inflammasome is activated to produce IL-1 $\beta$ which eventually leads to atherosclerotic lesions. As a part of innate immunity, CARD8 is involved in the modulation of above mentioned inflammatory activities. The primary objective of this study was to investigate the association between polymorphism of CARD8 rs2043211 and susceptibility to arteriosclerosis obliterans (ASO) in Chinese Han male population. Methods: 758 male arteriosclerosis obliterans patients and 793 male controls were genotyped for rs2043211 with the TaqMan allele assays. Fasting blood-glucose (FBG), total cholesterol (TC), triglycerides (TG), urea nitrogen, creatinine, Serum uric acid, high density lipoprotein, low density lipoprotein, ALT, AST, and IL-1 $\beta$ in the blood were detected for all subjects. Clinical data were recorded to analyze the genotype-phenotype. Independent samples t-test was used to perform the comparisons between two groups. Odds ratios (ORs) with $95 \%$ confidence intervals (CIs) were calculated to measure the strength of relationship in the genotype distribution and allele frequencies between patients and controls. The analysis of variance was used for a genotype-phenotype analysis of the ASO patients. Results: The genotypic and allelic frequencies in the ASO group were significantly different from that in the control group ( $P=0.014$ by genotype, $P=0.003$ by allele). Those carrying the genotype TT had a higher risk for ASO than those carrying the genotype AA (OR $=1.494,95 \%$ CI1.131-1.974, P = 0.005).The difference was also significant after the adjustment for the history of smoking, TC, $\mathrm{LDL}$, fasting blood glucose, systolic blood pressure and $\mathrm{BMI}(\mathrm{OR}=1.525,95 \% \mathrm{CI} 1.158-2.009$, $P=0.003$ ). Conclusion: Our finding suggests that the polymorphism of CARD8 rs2043211 is probably associated with the development of ASO in Chinese Han male population.




\section{Introduction}

Arteriosclerosis obliterans is characterized by the ischemic symptoms of lower extremity which are due to the stenosis and/or occlusion of artery based on the pathology of atherosclerotic change. This disease is relatively highly prevalent, affecting more than 200 million people worldwide [1]. Arteriosclerosis is caused by environmental and genetic factors [2]. In recent years, inflammatory factor has been proved participating in the atherosclerotic procedure [3-7]. It has been proved that cholesterol crystals can cause inflammation [8-10]. As a response to cholesterol crystal accumulation, the NLRP3 inflammasome is activated to produce IL-1 $\beta$ and IL-1 $\beta$ can cause atherosclerotic lesions $[11,12]$.NLRP3 inflammasome is consist of NLRP3 protein, apoptosis-associated speck (ASC)-like protein and caspase-1 protein $[13,14]$. The CARD8 (caspase recruitment domain family member 8) protein regulates this process by inhibiting the activation of NF- $\kappa B$ and caspase-1[15-17]. The CARD8 protein is encoded by the 13 exons of the CARD8 gene on chromosome 19q13. The SNP rs2043211 of CARD8 changes cysteine at codon10 to a premature termination codon, thus yielding a premature, truncated protein, which influences the protein function in inflammasome-mediated processes and NF- $\mathrm{BB}$ suppression $[18,19]$. Lots of studies show that the polymorphisms of CARD8 contribute to the development of some inflammatory diseases, such as inflammatory bowel disease [20-22], gout[23],abdominal aortic aneurysm[24], rheumatoid arthritis[17, 25, 26] and Alzheimer's disease[27, 28]. As a part of innate immunity, CARD8 is involved in the modulation of inflammatory activities. Because of the important role of CARD8 in inflammatory activities, we hypothesized that the polymorphism of CARD8 rs2043211 may be associated with the risk of arteriosclerosis obliterans development. To test this hypothesis, we designed the case-control study to validate the possible association between the polymorphism of CARD8 rs2043211 and arteriosclerosis obliterans in a Chinese Han male population.

\section{Materials and Methods}

\section{Study subjects, ethics and consent}

From March 2010 to January 2016, a total of 758 male patients with arteriosclerosis obliterans and 793 age-matched healthy male subjects were enrolled in the case-control study. Clinical and biological characteristics of the study participants are listed in Table 1 . All subjects were consecutively recruited from the Qingdao Municipal hospital. The diagnosis of arteriosclerosis obliterans was based on the guidelines released by ACCF/AHA in 2011 and 2012 [29, 30].Age over 40 years, the intermittent claudication and ischemic rest pain were used as the main diagnostic criteria, and the Ankle/Brachial Index $(A B I \leq 0.9)$ was used as complementary parameter. All ASO patients had been confirmed by CT angiography (CTA).Samples of controls without a personal or familial history of arteriosclerosis obliterans or other serious illness was collected. Fasting blood-glucose (FBG), total cholesterol (TC), triglycerides (TG), urea nitrogen, creatinine, Serum uric acid, high density lipoprotein, low density lipoprotein, ALT, AST, and IL-1 $\beta$ in the blood were detected for all subjects. Phenotypic characteristics including demographic data and disease duration were recorded using a standardized questionnaire. Every subject including control subject participating in this study received an explanation about the study before enrollment and had signed a written informed consent. The study protocol was approved by the Ethical Committee of the Qingdao Municipal hospital.

Plasma parameters determination

FBG was tested by glucose oxidase method. Serum uric acid, total cholesterol (TC), and triglycerides (TG) were tested by the oxides method. High density lipoprotein and low density lipoprotein were tested by selective inhibition method. Urea nitrogen, ALT and AST were tested by enzyme coupling method. Creatinine was tested by alkaline picrate method. All the parameters above were measured in an automatic biochemistry instrument(HITACHI 7600-120).And the expression level of IL-1 $\beta$ in plasma was measured by ELISA kit(R\&D Systems, Minneapolis, MN,USA), according to the manufacturer's instructions. 
Genotyping

Genomic DNA was extracted from peripheral venous blood using GenElute ${ }^{\mathrm{TM}}$ Blood Genomic DNA Kit (Sigma). The SNP of CARD8 rs2043211 was detected by using TaqMan SNP Genotyping Assays which contained a pair of primers, forward, 5'-AGTTGACACTCAGGAACAGCACGG A-3', and reverse, 5'-CAATAA TGGCTCTGCCTCTGTCTC A-3' (Applied Biosystem).The PCR was carried out in the ABI 7900HT Fast Real-Time PCR System, as the manufacturer's instructions. $10 \%$ of samples were analyzed repeatedly to confirm the accuracy of the TaqMan assays. Concordance rate between two times genotype calls was $100 \%$.

\section{Statistical analysis}

Statistical power was assessed using the Quanto 1.2.4 software. Assuming the ORs from 1.30 to 1.50 for these loci in Chinese, we obtained the estimated powers greater than $90 \%$ for the association of the SNP with the risk of ASO. SPSS version 20.0 software (IBM Corporation, USA) was used for the statistical analysis. Independent samples t-test was used to perform the comparisons between two groups. Pearson's $\chi 2$ test was used to test for deviations from Hardy-Weinberg equilibrium. Odds ratios (ORs) with $95 \%$ confidence intervals (CIs) were calculated to measure the strength of relationship in the genotype distribution and allele frequencies between patients and controls. The analysis of variance was used for a genotype-phenotype analysis of the ASO patients. Analysis was repeated taking into account the history of smoking. P-values $<0.05$ were considered to be statistically significant.

\section{Results}

\section{Clinical and biological characteristics}

Table 1 showed the clinical and biological characteristics of the subjects included in the study. It showed that age was significantly different between the two groups $(\mathrm{P}<0.05)$. And the levels of TC, LDL, IL-1 $\beta$, fasting blood glucose, systolic blood pressure and BMI in ASO patients group was much more higher than that in the controls $(\mathrm{P}<0.05)$. There was no obvious difference between ASO patients and controls in the other characteristics.

The polymorphism of CARD8 rs2043211 and ASO

No deviations from Hardy-Weinberg equilibrium were detected for the genotype distribution of CARD8 rs2043211 polymorphism in ASO patients or controls (P > 0.05). Table 2 showed the association between the polymorphism of CARD8 rs2043211 and ASO. It was obviously different in the genotype distribution of the polymorphism of CARD8 rs2043211 between ASO patients and controls $(\mathrm{P}=0.014)$. Those carrying genotype TT had a higher risk for ASO than those carrying genotype AA (OR $=1.494,95 \% \mathrm{CI} 1.131-1.974, \mathrm{P}=0.005)$ ,which was also significant after the adjustment of the history of smoking, TC, LDL, fasting blood glucose, systolic blood pressure and BMI(OR = 1.525, 95\%CI1.158-2.009, P=0.003). 


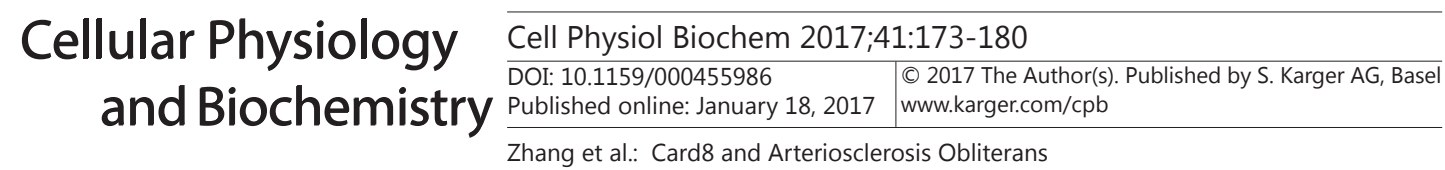

Table 2. Comparison of CARD8 rs2043211 polymorphism between ASO and controls. Footnote: a. after the adjustment of the history of smoking, TC, LDL, fasting blood glucose, systolic blood pressure, BMI and IL-1 $\beta$

\begin{tabular}{|c|c|c|c|c|c|c|}
\hline & ASO $(n=758)$ & Controls $(n=793)$ & $\mathrm{P}$ value & $\begin{array}{l}\mathrm{OR} \\
95 \% \mathrm{CI}\end{array}$ & P value ${ }^{a}$ & $\begin{array}{l}\mathrm{OR}^{\mathrm{a}} \\
95 \% \mathrm{CI}\end{array}$ \\
\hline \multicolumn{7}{|l|}{ Genotypes } \\
\hline $\mathrm{AA}(\%)$ & $191(25.20)$ & $249(31.40)$ & - & 1.000 & - & 1.000 \\
\hline $\mathrm{AT}(\%)$ & $371(48.94)$ & $373(47.04)$ & 0.032 & $\begin{array}{l}1.297 \\
1.023-1.644\end{array}$ & 0.027 & $\begin{array}{l}1.322 \\
1.045-1.671\end{array}$ \\
\hline $\mathrm{TT} \quad(\%)$ & $196(25.86)$ & $171(21.56)$ & 0.005 & $\begin{array}{l}1.494 \\
1.131-1.974\end{array}$ & 0.003 & $\begin{array}{l}1.525 \\
1.158-2.009\end{array}$ \\
\hline \multicolumn{7}{|l|}{ Alleles } \\
\hline A $(\%)$ & $753(49.67)$ & $871(54.92)$ & - & 1.000 & - & 1.000 \\
\hline $\mathrm{T}(\%)$ & $763(50.33)$ & $715(45.08)$ & 0.003 & $\begin{array}{l}1.234 \\
1.072-1.421\end{array}$ & 0.002 & $\begin{array}{l}1.252 \\
1.088-1.443\end{array}$ \\
\hline
\end{tabular}

Table 3. Genotype-phenotype analysis in our study(BMI, Body mass index; TG, Triglycerides; TC, Total cholesterol, IL-1 $\beta$,etc.) ( $\bar{x} \pm S)$

\begin{tabular}{|c|c|c|c|c|c|}
\hline Characteristic & $\begin{array}{l}\text { AA } \\
(n=191)\end{array}$ & $\begin{array}{l}\text { AT } \\
(n=371)\end{array}$ & $\begin{array}{l}\text { TT } \\
(n=196)\end{array}$ & $\begin{array}{l}\text { P value for } \\
\text { ANOVA } \\
\text { analysis } \\
\end{array}$ & $\begin{array}{l}\text { P value for } \\
\text { AA vs. TT }\end{array}$ \\
\hline Age(years) & $61.35 \pm 10.27$ & $61.43 \pm 10.83$ & $61.98 \pm 11.15$ & 0.453 & 0.314 \\
\hline $\begin{array}{l}\text { Age at } \\
\text { diagnosis(years) }\end{array}$ & $55.18 \pm 12.16$ & $54.79 \pm 11.24$ & $54.92 \pm 11.58$ & 0.389 & 0.371 \\
\hline $\begin{array}{l}\text { Disease } \\
\text { duration(years) }\end{array}$ & $7.85 \pm 3.53$ & $7.03 \pm 3.69$ & $7.68 \pm 3.47$ & 0.114 & 0.233 \\
\hline $\mathrm{BMI}\left(\mathrm{kg} / \mathrm{m}^{2}\right)$ & $26.65 \pm 3.09$ & $27.12 \pm 3.12$ & $26.98 \pm 3.27$ & 0.237 & 0.238 \\
\hline $\begin{array}{l}\text { systolic pressure } \\
\text { (mmHg) }\end{array}$ & $130.98 \pm 8.91$ & $130.26 \pm 9.06$ & $130.64 \pm 8.93$ & 0.386 & 0.415 \\
\hline $\begin{array}{l}\text { diastolic pressure } \\
(\mathrm{mmHg})\end{array}$ & $79.83 \pm 9.32$ & $80.58 \pm 8.67$ & $80.29 \pm 8.45$ & 0.423 & 0.302 \\
\hline $\mathrm{FBG}(\mathrm{mmol} / \mathrm{L})$ & $6.33 \pm 0.41$ & $6.53 \pm 0.37$ & $6.48 \pm 0.45$ & 0.543 & 0.597 \\
\hline $\begin{array}{l}\text { Serum uric acid } \\
(\mu \mathrm{mo} 1 / \mathrm{L})\end{array}$ & $\begin{array}{l}303.89 \pm 50.4 \\
5\end{array}$ & $\begin{array}{l}314.11 \pm 51.0 \\
2\end{array}$ & $\begin{array}{l}306.12 \pm 50.7 \\
1\end{array}$ & 0.329 & 0.577 \\
\hline $\mathrm{TG}(\mathrm{mmol} / \mathrm{L})$ & $1.49 \pm 0.37$ & $1.52 \pm 0.31$ & $1.57 \pm 0.29$ & 0.255 & 0.234 \\
\hline $\mathrm{TC}(\mathrm{mmol} / \mathrm{L})$ & $5.75 \pm 0.48$ & $5.39 \pm 0.57$ & $5.69 \pm 0.54$ & 0.242 & 0.377 \\
\hline $\mathrm{HDL}(\mathrm{mmol} / \mathrm{L})$ & $1.43 \pm 0.46$ & $1.37 \pm 0.39$ & $1.39 \pm 0.41$ & 0.463 & 0.474 \\
\hline $\mathrm{LDL}(\mathrm{mmol} / \mathrm{L})$ & $2.85 \pm 0.49$ & $3.22 \pm 0.36$ & $3.63 \pm 0.43$ & 0.037 & 0.022 \\
\hline $\mathrm{BUN}(\mathrm{mmol} / \mathrm{L})$ & $5.17 \pm 1.34$ & $5.07 \pm 1.19$ & $5.09 \pm 1.41$ & 0.702 & 0.707 \\
\hline $\operatorname{Cr}(\mu \mathrm{mo} 1 / \mathrm{L})$ & $76.92 \pm 8.57$ & $77.08 \pm 9.45$ & $77.54 \pm 9.23$ & 0.426 & 0.387 \\
\hline ALT(U/L) & $39.08 \pm 7.32$ & $38.90 \pm 7.08$ & $38.59 \pm 7.47$ & 0.471 & 0.396 \\
\hline $\operatorname{AST}(U / L)$ & $29.13 \pm 6.12$ & $28.92 \pm 5.36$ & $28.55 \pm 5.25$ & 0.216 & 0.169 \\
\hline IL-1 $\beta(\mathrm{ng} / \mathrm{L})$ & $7.94 \pm 0.93$ & $8.31 \pm 1.02$ & $8.75 \pm 1.06$ & 0.014 & 0.019 \\
\hline
\end{tabular}

Genotype-phenotype analysis

The results of genotype-phenotype analysis were showed in Table 3. It was obviously different in the LDL levels among those three genotypes. There was also significant difference in the levels of IL- $1 \beta$ between individuals carrying the TT, AT and AA genotype of rs2043211 $(\mathrm{P}=0.014)$. Patients carrying genotype TT of CARD8 rs2043211 polymorphism had higher LDL levels compared to those carrying the AA genotype $(3.63 \pm 0.43 \mathrm{mmol} / \mathrm{L}$ vs. $2.85 \pm 0.49$ $\mathrm{mmol} / \mathrm{L}, \mathrm{P}=0.022$ ). Patients carrying the TT genotype also had an increased IL-1 $\beta$ level compared with those carrying the AA genotype $(\mathrm{P}=0.019)$. 


\section{Cellular Physiology Cell Physiol Biochem 2017;41:173-180 \begin{tabular}{ll|l} 
and Biochemistry Published onIIne: January 18, 2017 & $\begin{array}{l}\text { (c) } 2017 \text { The Author(s). Published by S. Karger AG, Basel } \\
\text { www.karger.com/cpb }\end{array}$ \\
\hline
\end{tabular} \\ Zhang et al.: Card8 and Arteriosclerosis Obliterans}

\section{Discussion}

As a kind of autoinflammatory disorder, arteriosclerosis obliterans is histologically typified by atherosclerotic thickening, loss of elasticity, and medial calcification of the arterial walls [31]. Recent studies have showed that cholesterol crystals activate the NLRP3 inflammasome in phagocytes in vitro in a process that involves phagolysosomal damage [11]. The NLRP3 inflammasome, including CARD8 can control inflammatory caspase-1-mediated IL-1 $\beta$ release and is involved in cholesterol crystals mediated arteriosclerosis [11, 32].

We performed the case-control study to examine the possible genetic association between CARD8 rs2043211 polymorphism and ASO in a Chinese Han male population. We found that there was an obvious difference in the genotype distribution of CARD8 rs2043211 polymorphism between cases and controls $(\mathrm{P}=0.014)$. After the adjustment of the history of smoking, TC, LDL, fasting blood glucose, systolic blood pressure and BMI, those carrying genotype TT had a higher risk for ASO than those carrying genotype AA (OR $=1.525$, $95 \%$ CI1.158-2.009, $\mathrm{P}=0.003$ ). As far as we know, this is the first study to report the association between polymorphisms of CARD8 and ASO. In contrast to coronary atherosclerotic heart disease, few genetic variants that influence susceptibility to ASO have been discovered. Susceptibility to ASO may be influenced by genetic variants acting independently of those risk factors, such as smoking, diabetes mellitus, hypertension and hyperlipidaemia etc. Identification of such genetic variants will provide insights into underlying pathophysiologic mechanisms of ASO. Our study result will be helpful in increasing our understanding of the molecular genetics of ASO and in facilitating the development of novel diagnostic and therapeutic approaches for this disease.

In the genotype-phenotype analysis, we found that LDL levels showed a significantly different distribution among those three different genotypes. Patients carrying genotype TT showed higher LDL levels compared to those carrying the genotype AA. LDL can raise the risk of ASO [33-35], and the genotype-phenotype analysis indicates that CARD8 rs2043211 polymorphism is associated with LDL levels, which further proves the association between CARD8 rs2043211 polymorphism and susceptibility to ASO.

The secretion of the IL- $1 \beta$ by macrophages is a major driver of pathogenesis in atherosclerosis [36]. As a response to cholesterol crystal accumulation, the NLRP3 inflammasome is activated to produce IL-1 $\beta[11,12]$. The CARD8 protein regulates this process by inhibiting the activation of NF- $\mathrm{KB}$ and caspase-1[15-17].The CARD8 protein can negatively regulate caspase-1-mediated IL-1 $\beta$ expression and nuclear factor NF- $\kappa B$ activation $[37,38]$. The SNP rs2043211 introduces a stop codon polymorphism (Cys10Stop), which results in the expression of a severely truncated protein. The variant protein can not

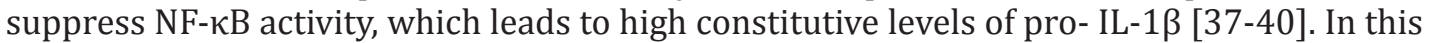
study, the results showed that the prevalence of the TT variant genotype was much higher in ASO patients than in controls. So, it is possible that the over expression of CARD8 due to higher promoter activity of the TT genotype may result in a dramatically inflammatory immune response and then increase the susceptibility to ASO.

However, our study had some limitations. Firstly, we only chose the SNP rs2043211 of CARD8 and did not include all the SNPs to cover the whole sequence of CARD8 gene. Secondly, the sample size in the present study was not big enough, and all subjects were selected from Chinese Han male population. Thus, the results should be interpreted carefully. Our results need to be verified in more studies with larger sample and in other ethic populations. Thirdly, the mechanism about the association between CARD8 rs2043211 polymorphism and susceptibility to ASO is still unknown. Further studies are needed to explore the mechanism underling CARD8 rs2043211 polymorphism and susceptibility to ASO.

In conclusion, CARD8 rs2043211 polymorphism is significantly associated with susceptibility to ASO in Chinese Han males. However, our findings need to be verified in more studies with expanding sample and in other ethic populations. 


\section{Cellular Physiology Cell Physiol Biochem 2017;41:173-180

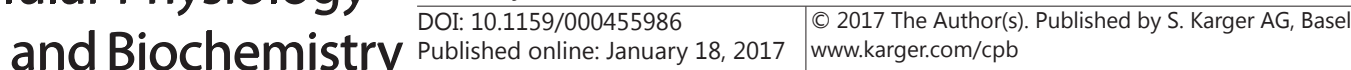

Zhang et al.: Card8 and Arteriosclerosis Obliterans

\section{Acknowledgments}

We are thankful to all the ASO patients and healthy controls who participated in this study. This work was supported by grants from science and technology support project in Qingdao (2010-3-3-4-17-nsh).

\section{Disclosure Statement}

All authors declare that they have no conflicts of interest.

\section{References}

- 1 Fowkes FG RD, Rudan I AV, Denenberg JO MMM, Norman PE SUK, Williams LJ MGA, Criqui MH: Comparison of global estimates of prevalence and risk factors for peripheral artery disease in 2000 and2010: a systematic review and analysis. Lancet 2013;382:1329-1340.

-2 Zhu XF, Shan Z, Ma JY, Wang M, Zhang CX, Liu RM, Wu WB, Shi YW, Li W, Wang SM: Investigating the Role of the Posttranscriptional Gene Regulator MiR-24- 3p in the Proliferation, Migration and Apoptosis of Human Arterial Smooth Muscle Cells in Arteriosclerosis Obliterans. Cell Physiol Biochem 2015;36:1359-1370.

3 Shapiro MD, Fazio S: From Lipids to Inflammation: New Approaches to Reducing Atherosclerotic Risk. Circ Res 2016;118:732-749.

4 Sorci-Thomas MG, Thomas MJ: Microdomains, Inflammation, and Atherosclerosis. Circ Res 2016;118:679691.

-5 Usman A, Ribatti D, Sadat U, Gillard JH: From Lipid Retention to Immune-Mediate Inflammation and Associated Angiogenesis in the Pathogenesis of Atherosclerosis. J Atheroscler Thromb 2015;22:739-749. Nagasawa SY, Ohkubo T, Masaki K, Barinas-Mitchell E, Miura K, Seto T, El-Saed A, Kadowaki T, Willcox BJ, Edmundowicz D, Kadota A, Evans RW, Kadowaki S, Fujiyoshi A, Hisamatsu T, Bertolet MH, Okamura T, Nakamura Y, Kuller LH, Ueshima H, Sekikawa A: Associations between Inflammatory Markers and Subclinical Atherosclerosis in Middle-aged White, Japanese-American and Japanese Men: The ERA-JUMP Study. J Atheroscler Thromb 2015;22:590-598.

7 Yang Y, Yang L, Liang X, Zhu G: MicroRNA-155 Promotes Atherosclerosis Inflammation via Targeting SOCS1. Cell Physiol Biochem 2015;36:1371-1381.

8 Varsano N, Fargion I, Wolf SG, Leiserowitz L, Addadi L: Formation of 3D cholesterol crystals from 2D nucleation sites in lipid bilayer membranes: implications for atherosclerosis. J Am Chem Soc 2015;137:1601-1607.

-9 Bendtzen K, Christensen 0, Nielsen CH, Holmstrup P: A matrix of cholesterol crystals, but not cholesterol alone, primes human monocytes/macrophages for excessive endotoxin-induced production of tumor necrosis factor-alpha. Role in atherosclerotic inflammation. Discov Med 2014;17:309-312.

10 Grebe A, Latz E: Cholesterol crystals and inflammation. Curr Rheumatol Rep 2013;15:313.

-11 Duewell P, Kono H, Rayner KJ, Sirois CM, Vladimer G, Bauernfeind FG, Abela GS, Franchi L, Nuñez G, Schnurr M, Espevik T, Lien E, Fitzgerald KA, Rock KL, Moore KJ, Wright SD, Hornung V, Latz E: NLRP3 inflammasomes are required for atherogenesis and activated by cholesterol crystals. Nature 2010;464:1357-1361.

12 Eun SY, Ko YS, Park SW, Chang KC, Kim HJ: IL-1 $\beta$ enhances vascular smooth muscle cell proliferation and migration via P2Y2 receptor-mediated RAGE expression and HMGB1 release. Vascul Pharmacol 2015;72:108-117.

-13 Lopes AH, Talbot J, Silva RL, Lima JB, França RO, Verri WA, Mascarenhas DP, Ryffel B, Cunha FQ, Zamboni DS, Cunha TM: Peripheral NLCR4 inflammasome participates in the genesis of acute inflammatory pain. Pain 2015;156:451-459.

14 Liao J, Kapadia VS, Brown LS, Cheong N, Longoria C, Mija D, Ramgopal M, Mirpuri J, McCurnin DC, Savani RC: The NLRP3 inflammasome is critically involved in the development of bronchopulmonary dysplasia. Nat Commun 2015;6:8977. 


\section{Cellular Physiology Cell Physiol Biochem 2017;41:173-180

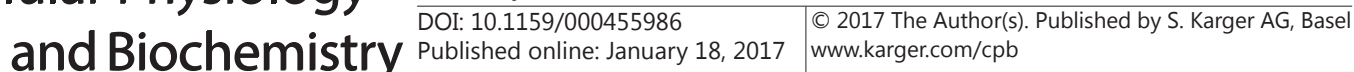

Zhang et al.: Card8 and Arteriosclerosis Obliterans

-15 Razmara M, Srinivasula SM, Wang L, Poyet JL, Geddes BJ, DiStefano PS, Bertin J, Alnemri ES: CARD-8 protein, a new CARD family member that regulates caspase- 1 activation and apoptosis. J Biol Chem 2002;277:13952-13958.

-16 Ko DC, Shukla KP, Fong C, Wasnick M, Brittnacher MJ, Wurfel MM, Holden TD, O'Keefe GE, Van Yserloo B, Akey JM, Miller SI: A genome-wide in vitro bacterial-infection screen reveals human variation in the host response associated with inflammatory disease. Am J Hum Genet 2009;85:214-227.

17 Fontalba A, Martinez-Taboada V, Gutierrez O, Pipaon C, Benito N, Balsa A, Blanco R, Fernandez-Luna JL: Deficiency of the NF-kappaB inhibitor caspase activating and recruitment domain 8 in patients with rheumatoid arthritis is associated with disease severity. J Immunol 2007;179:4867-4873.

-18 García-Bermúdez M, López-Mejías R, González-Juanatey C, Corrales A, Castañeda S, Ortiz AM, MirandaFilloy JA, Gómez-Vaquero C, Fernández-Gutiérrez B, Balsa A, Pascual-Salcedo D, Blanco R, Llorca J, Martín J, González-Gay MA: CARD8 rs2043211 (p.C10X) polymorphism is not associated with disease susceptibility or cardiovascular events in Spanish rheumatoid arthritis patients. DNA Cell Biol 2013;32:28-33.

19 Vasseur F, Sendid B, Broly F, Gower-Rousseau C, Sarazin A, Standaert-Vitse A, Colombel JF, Poulain D, Jouault T: The CARD8 p.C10X mutation associates with a low anti-glycans antibody response in patients with Crohn's disease. BMC Med Genet 2013;14:35.

20 Liu J, Liu YY, Liu J, Li BZ, Cen H, Xu WD, Leng RX, Pan HF, Ye DQ: Association between CARD8 rs2043211 Polymorphism and Inflammatory Bowel Disease: A Meta-Analysis. Immunol Invest 2015;44:253-264.

-21 Roberts RL, Topless RK, Phipps-Green AJ, Gearry RB, Barclay ML, Merriman TR: Evidence of interaction of CARD8 rs2043211 with NALP3 rs35829419 in Crohn's disease. Genes Immun 2010;11:351-356.

22 Yang SK, Kim H, Hong M, Lim J, Choi E, Ye BD, Park SK, Song K: Association of CARD8 with inflammatory bowel disease in Koreans. J Hum Genet 2011;56:217-223.

23 Chen Y, Ren X, Li C, Xing S, Fu Z, Yuan Y, Wang R, Wang Y, Lv W: CARD8 rs2043211 polymorphism is associated with gout in a Chinese male population. Cell Physiol Biochem 2015;35:1394-1400.

-24 Roberts RL, Van Rij AM, Phillips LV, Young S, McCormick SP, Merriman TR, Jones GT: Interaction of the inflammasome genes CARD8 and NLRP3 in abdominal aortic aneurysms. Atherosclerosis 2011;218:123126.

25 Kastbom A, Johansson M, Verma D, Söderkvist P, Rantapää-Dahlqvist S: CARD8 p.C10X polymorphism is associated with inflammatory activity in early rheumatoid arthritis. Ann Rheum Dis 2010;69:723-726.

26 Kastbom A, Verma D, Eriksson P, Skogh T, Wingren G, Söderkvist P: Genetic variation in proteins of the cryopyrin inflammasome influences susceptibility and severity of rheumatoid arthritis (the Swedish TIRA project). Rheumatology (Oxford) 2008;47:415-417.

27 Fontalba A, Gutiérrez O, Llorca J, Mateo I, Vázquez-Higuera JL, Berciano J, Fernández-Luna JL, Combarros 0: Gene-gene interaction between CARD8 and interleukin-6 reduces Alzheimer's disease risk. J Neurol 2009;256:1184-1186.

28 Fontalba A, Gutiérrez O, Llorca J, Mateo I, Berciano J, Fernández-Luna JL, Combarros O: Deficiency of CARD8 is associated with increased Alzheimer's disease risk in women. Dement Geriatr Cogn Disord 2008;26:247250.

-29 Rooke TW, Hirsch AT, Misra S, Sidawy AN, Beckman JA, Findeiss LK, Golzarian J, Gornik HL, Halperin JL, Jaff MR, Moneta GL, Olin JW, Stanley JC, White CJ, White JV, Zierler RE: 2011 ACCF/AHA focused update of the guideline for the management of patients with peripheral artery disease (updating the 2005 guideline). Vasc Med 2011;16:452-476.

-30 Creager MA, Belkin M, Bluth EI, Casey DE, Chaturvedi S, Dake MD, Fleg JL, Hirsch AT, Jaff MR, Kern JA, Malenka DJ, Martin ET, Mohler ER, Murphy T, Olin JW, Regensteiner JG, Rosenwasser RH, Sheehan P, Stewart KJ, Treat-Jacobson D, Upchurch GR, White CJ, Ziffer JA, Hendel RC, Bozkurt B, Fonarow GC, Jacobs JP, Peterson PN, Roger VL, Smith EE, Tcheng JE, Wang T, Weintraub WS: 2012 ACCF/AHA/ACR/SCAI/SIR/STS/ SVM/SVN/SVS key data elements and definitions for peripheral atherosclerotic vascular disease: a report of the American College of Cardiology Foundation/American Heart Association Task Force on Clinical Data Standards (Writing Committee to Develop Clinical Data Standards for Peripheral Atherosclerotic Vascular Disease). Circulation 2012;125:395-467.

-31 Liu J, Li W, Wang S, Wu Y, Li Z, Wang W, Liu R, Ou J, Zhang C, Wang S: MiR-142-3p attenuates the migration of $\mathrm{CD} 4^{+} \mathrm{T}$ cells through regulating actin cytoskeleton via RAC1 and ROCK2 in arteriosclerosis obliterans. PLoS One 2014;9:e95514. 


\section{Cellular Physiology Cell Physiol Biochem 2017;41:173-180

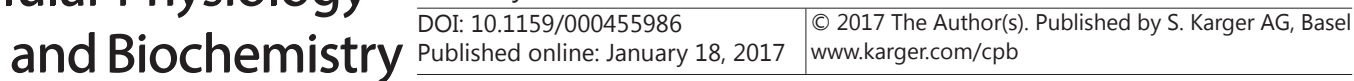 \\ Zhang et al.: Card8 and Arteriosclerosis Obliterans}

-32 Li X, Zhang Y, Xia M, Gulbins E, Boini KM, Li PL: Activation of Nlrp3 inflammasomes enhances macrophage lipid-deposition and migration: implication of a novel role of inflammasome in atherogenesis. PLoS One 2014;9:e87552.

33 Kamimura M, Matsuo M, Miyahara T, Kimura K, Matsumoto K, Nakaya T, Abe T, Akizawa T: Improvements in artery occlusion by low-density lipoprotein apheresis in a patient with peripheral arterial disease. Ther Apher 2002;6:467-470.

-34 Nakamura T, Matsuda T, Suzuki Y, Ueda Y, Koide H: Effects of low-density lipoprotein apheresis on plasma matrix metalloproteinase- 9 and serum tissue inhibitor of metalloproteinase- 1 levels in diabetic hemodialysis patients with arteriosclerosis obliterans. ASAIO J 2003;49:430-434.

-35 Suzuki T, Sato Y, Niizuma S, Kushiro T, Tani S, Ishikawa K, Kajiwara N, Kanmatsuse K, Ikeda H, Takahashi M, Kojima S: Efficacy of low-density lipoprotein apheresis in arteriosclerosis obliterans of the lower extremities: two cases with marked alleviation of clinical symptoms. J Clin Apher 2007;22:287-291.

-36 Warnatsch A, Ioannou M, Wang Q, Papayannopoulos V: Inflammation. Neutrophil extracellular traps license macrophages for cytokine production in atherosclerosis. Science 2015;349:316-320.

- 37 Srinivasula SM, Poyet JL, Razmara M, Datta P, Zhang Z, Alnemri ES: The PYRIN-CARD protein ASC is an activating adaptor for caspase-1. J Biol Chem 2002;277:21119-21122.

- 38 Razmara M, Srinivasula SM, Wang L, Poyet JL, Geddes BJ, DiStefano PS, Bertin J, Alnemri ES: CARD-8 protein, a new CARD family member that regulates caspase-1 activation and apoptosis. J Biol Chem 2002;277:13952-13958.

-39 Fontalba A, Martinez-Taboada V, Gutierrez O, Pipaon C, Benito N, Balsa A, Blanco R, Fernandez-Luna JL: Deficiency of the NF-kappaB inhibitor caspase activating and recruitment domain 8 in patients with rheumatoid arthritis is associated with disease severity. J Immunol 2007;179:4867-4873.

40 Bagnall RD, Roberts RG, Mirza MM, Torigoe T, Prescott NJ, Mathew CG: Novel isoforms of the CARD8 (TUCAN) gene evade a nonsense mutation. Eur J Hum Genet 2008;16:619-625. 